The morning and afternoon sessions of the first day were allotted to a discussion of the teaching of postgraduate physics in Indian universities. While welcoming the guests, Dr. P. C. Bhattacharya, head of the Department of Physics, University of Calcutta, gave a brief account of his Department, first established in 1916, in which such eminent scientists as Sir C. V. Raman, Dr. D. M. Bose, the late Dr. M. N. Saha, Dr. S. K. Mitra and Prof. S. N. Bose worked and inspired the younger generation. Dr. D. M. Bose, director of the Bose Institute, in his presidential address, first gave a description of the teaching of physics in his college days in the Presidency College, Calcutta (1905-6), in Cambridge (1907-11), in London (1911-12) and Berlin (1914-18), under J. C. Bose, J. J. Thomson, C. T. R. Wilson, Jeans, Watson, Rubens, Max Planck and others. He also mentioned the methods of teaching of Einstein and Nernst. As a professor of physies, Dr. Bose revised the M.Se. syllabus in physics for the University of Calcutta in 1920 on the lines adopted by Planck. Dr. Bose discussed the feasibility of devising a satisfactory sylla. bus for teaching postgraduate physics in all the universities in India. Young men after getting the degree of M.Sc. generally take up (1) the teaching of physics in high schools and colleges, (2) research work in the universities, government laboratories and industry, (3) administrative work in government, technical and commercial services; and Dr. Bose stressed the importance of the first category to the economic and technological development of India.

Finally, Dr. Bose dealt with the importance of encouraging nuclear research through non-governmental agencies. Like Brookhaven National Laboratory for research and training in nuclear physics which is managed by nine United States universities, he pleaded that similar laboratories should be established in India on a regional basis.

Dr. Buechner gave an impression of his two months tour of India, visiting various universities and institutions. He remarked upon certain similarities between India and the United States as regards the type of student who undertakes postgraduate studies and the lack of financial support for universities. One striking difference is that in the United States, although there are a number of laboratories managed by the government or by industry, the prime centre of research is the university. This is not the case in India, where Dr. Buechner had the impression that the universities are steadily declining in importance, being overshadowed by government and other research institutions. Without government support research cannot flourish, and without research any programme of postgraduate teaching will fail. It is the responsibility of the Indian universities to put forward their claims to the authorities and to make them understand the place of research in the university and in postgraduate teaching.

Sixteen other speakers, mostly heads of departments of physics in various universities, also gave accounts of the methods of postgraduate teaching prevailing in their respective universities, with suggestions for improvements.

The teachers of physies present at the seminar, representing almost all the universities of India, finally resolved (inter alia) that :

"As the main burden of the training of future physicists must be borne by the universities, the University Grants Commission is requested to ensure that the emoluments, research grants and other facilitios available to the university teachers are adequate and in no way inferior to those available to people in similar positions in the National Laboratories or elsewhere."

The conference viewed with concern the general tendency for men with the best university qualifications to leave their universities for more lucrative jobs elsewhere, including the administrative services in which a knowledge of physics is not necessary, when their knowledge is urgently required for teaching work in the universities. "The best tools must be retained for manufacturing the tools themselves, for this in turn will produce better and better tools." P. C. Bhattacharya

\section{WATER QUALITY PROBLEMS IN THE UNITED KINGDOM}

$\Delta \mathrm{T}$ a meeting of the Society for Visiting Scientists A held on Oetober 22, under the chairmanship of Mr. H. W. Cremer, there was an interesting discussion on "Water Quality Problems in the United Kingdom" following short papers on different aspects of this subject by Dr. G. Carter (Metropolitan Water Board), Dr. A. Key (Ministry of Housing and Local Government), and Dr. B. A. Southgate (Water Pollution Research Laboratory).

There is a growing demand for water of good quality, not only for domestic use, but also for industry-in some processes of manufacture the specifications to which the water must conform are more stringent than for drinking water-and for agriculture, particu. larly for drinking water for attested cattle. To produce water of this high quality from surface supplies a wide range of treatment processes is used; the Metropolitan Water Board, for example, treats Thames water by storage, filtration through rapid and slow sand-filters, and chlorination; industrial supplies may be treated in plants resembling those of municipal water undertakings, and for some purposes may be de-ionized by exchange processes ; drinking water for cattle is often chlorinated before use.

At the same time the total volume of water asked for is also rapidly increasing. Usually, whether used for domestic or industrial purposes, the volume returned to a stream is substantially the same as that extracted, the problem being so to treat it that it can, if necessary, be used again farther downstream. For sewage, satisfactory methods of treatment are available, and by taking special precautions-as, for example, by passing the treated sewage effluent, through sand-filters-the liquid finally returned to a river may be brought to a high standard of quality, and indeed would often be suitable, after chlorination, for some industrial purposes. Waste waters from industrial processes, having a much wider range of composition, present more difficult problems in treatment.

The large amount of research on these problems now being undertaken, or sponsored, by industry was widely recognized in the discussion. Several speakers referred to the difficult situation which may arise if there is any great increase in the practice of irrigating farm crops in the drier parts of Britain; water used in this way is lost from the cycle of use and re-use, being, of course, evaporated or transpired by plants. 